\title{
Reduced expression of nicotinic AChRs in myotubes from spinal muscular atrophy I patients
}

\author{
Anne-Sophie Arnold ${ }^{1}$, Mor Gueye ${ }^{1}$, Séverine Guettier-Sigrist ${ }^{2}$, Isabelle Courdier-Fruh ${ }^{3}$, \\ Gilliane Coupin ${ }^{1}$, Philippe Poindron ${ }^{1}$ and Jean-Pierre Gies ${ }^{1}$ \\ ${ }^{1}$ Laboratoire de Pathologie des Communications entre Cellules Nerveuses et Musculaires (LPCCNM), EA \\ 3429, Université Louis Pasteur, Faculté de Pharmacie, Illkirch, France; ${ }^{2}$ Centre Européen d'Etude sur le \\ Diabète (CEED), Faculté de Médecine, Strasbourg, France and ${ }^{3}$ MyoContract Pharmaceutical Research Ltd, \\ Basel, Switzerland
}

\begin{abstract}
Spinal muscular atrophy (SMA) is an autosomal recessive disorder characterized by degeneration of motoneurons and skeletal muscle atrophy. In its most severe form, it leads to death before the age of 2 years. While primary degeneration of motor neurons is well established in this disease, and this results in neurogenic atrophy of skeletal muscle, we have previously reported evidence for a primary muscle defect. In this study, we used primary cultures of embryonic human skeletal muscle cells from patients with SMA and from controls to examine the effects of muscle fiber differentiation in the absence of a nerve component. Cultured SMA skeletal muscle cells are unable to fuse correctly to form multinuclear myotubes, the precursors of the myofibers. We also show that agrin-induced aggregates of nicotinic acetylcholine receptors, one of the earliest steps of neuromuscular junction formation, cannot be visualized by confocal microscopy on cells from SMA patients. In binding experiments, we demonstrate that this lack of clustering is due to defective expression of the nicotinic acetylcholine receptors in the myotubes of SMA patients whereas the affinity of $\alpha$-bungarotoxin for its receptor remains unchanged regardless of muscle cell type (SMA or control). These observations suggest that muscle cells from SMA patients have intrinsic abnormalities that may affect proper formation of the neuromuscular junction.
\end{abstract}

Laboratory Investigation (2004) 84, 1271-1278, advance online publication, 23 August 2004; doi:10.1038/labinvest.3700163

Keywords: spinal muscular atrophy; myotubes; neuromuscular junction; nicotinic acetylcholine receptors; aggregation; binding

Spinal muscular atrophy (SMA) is a neuromuscular disorder characterized by degeneration of spinal motor neurons leading to a muscle weakness and paralysis. SMA is traditionally classified into three types based on the age of onset and the severity of symptoms. ${ }^{1}$ The SMA I or Werdnig-Hoffmann disease is the most severe form. Patients never attain the ability to sit, and their lifespan does not exceed infancy in most cases. SMA II is the intermediate form. Patients are unable to stand or walk unaided, and death usually occurs in adulthood. SMA III or Kugelberg-Welander disease presents a milder phenotype. Patients are able to

Correspondence: Professor J-P Gies, PhD, Université Louis Pasteur, Strasbourg I, Faculté de Pharmacie, LPCCNM, 74 route du Rhin, BP 60024, 67401 Illkirch Cedex, France.

E-mail: jean-pierre.gies@pharma.u-strasbg.fr

Received 20 October 2003; revised 6 June 2004; accepted 10 June 2004; published online 23 August 2004 stand and walk and present a near-normal life expectancy. The gene responsible for all three types of SMA was mapped to the region 5q11.2-13.3 by linkage analysis. ${ }^{2-5}$

This gene, named $S M N$ for 'survival of motor neurons', is mutated in $98 \%$ of the SMA patients, and the majority of mutations occur in exon $7 .{ }^{6}$ It encodes a ubiquitously expressed SMN protein present in both the cytoplasm and the nucleus. In this last compartment, the SMN protein is concentrated in structures called gems (for 'gemini of coiled bodies') located in the close proximity of Cajal bodies (previously named coiled bodies). ${ }^{7,8}$ The SMN protein participates in the formation of the SMN complex, which is associated with small nuclear ribonucleoproteins (snRNP) in the cytoplasm and plays a crucial role in the spliceosomal snRNP assembly. ${ }^{9}$ In the nucleus, the SMN complex participates in the regeneration of spliceosomes. ${ }^{10-12}$ The expression of SMN was studied in several 
control and SMA tissue and a decrease of SMN protein in fetal spinal cord ${ }^{13,14}$ and in fetal muscle ${ }^{15}$ of SMA I patients was demonstrated. A reduction in SMN protein level during postnatal development and a lack of SMN in skeletal muscles of SMA fetuses might be correlated with defects of muscle fibers. These observations suggest that SMA is a prenatal rather than a postnatal disease. ${ }^{15}$

The molecular mechanism leading to SMA is still unknown. The SMN protein is ubiquitously expressed and the deficiency in SMN expression is observed not only in motor neurons but also in other tissues from SMA patients. However, why this deficiency has an effect only in the neuromuscular system remains to be elucidated. To study this disease, we have previously used a model of nerve-muscle coculture consisting of human muscle cells innervated by rat embryonic spinal cords explants. ${ }^{16}$ Using this system, we demonstrated that SMA could result from a muscular defect and that the motor neuron degeneration is not sufficient to explain the entire SMA phenotype. ${ }^{17}$ We highlighted a specific degeneration of myofibers originating from SMA I and II (but not III) patients in the cocultures. ${ }^{17}$ We also proved that this degeneration could not be attributed to the production of a toxic factor or to the lack of secretion of a trophic factor, ${ }^{18}$ and that the cells responsible for this degeneration were muscle cells. ${ }^{19}$ Based on these observations, we hypothesized that myotubes from SMA patients could be innervated and contracted as normal myotubes, but were unable to produce SMN-dependent signal essential for motoneuron survival. ${ }^{20}$ This muscular hypothesis was confirmed by the fact that the deletion of $S M N$ exon 7, the most frequently mutated exon in SMA, led to severe muscular dystrophy, proving that skeletal muscle is a target of the SMN gene defect, and confirming our idea that muscle involvement contributes to the motor defect in human SMA disease. ${ }^{21}$ More recently, a deletion of $S M N$ exon 7 was directed either to both satellite cells (the muscle progenitor cells) and fused myotubes, or to fused myotubes only. This showed that the intact satellite cells improved the survival and motor performance of mutant mice suggesting a potential of satellite cells to regenerate skeletal muscle. ${ }^{22}$

Neuromuscular junctions (NMJs) are highly specialized structures in which nerve and muscle play a fundamental role. ${ }^{23}$ Postsynaptic differentiation at the vertebrate neuromuscular junction is characterized by aggregation of numerous proteins. This process depends on instructive signals that are released by the motor axon. For example, aggregation of nicotinic acetylcholine receptors (nAChRs) is induced by agrin, a protein released from the neural synaptic basal lamina. ${ }^{24,25}$ It represents the earliest step of the NMJ installation. When added to cultured myotubes, soluble agrin induces the aggregation of nAChRs in a dose-dependent manner, suggesting that agrin plays a role in postsynaptic differentiation. ${ }^{26}$ The combination of agrin on its receptor induces an intracellular signalling cascade that includes tyrosine phosphorylation of the AChR itself and of the muscle-specific receptor tyrosine kinase, MuSK. ${ }^{27,28}$ Both are phosphorylated rapidly after addition of agrin. The interaction of agrin with MuSK results in the activation of the nonreceptor tyrosine kinases Abl-1 and Abl-2, which directly influence the actin cytoskeleton, ${ }^{29}$ confirming similarities between AChR aggregation and focal adhesion formation. A recent study demonstrated a role for the soluble guanylyl cyclase in the aggregation of the AChR via local formation of NO. ${ }^{30}$

To confirm the involvement of muscle in SMA pathogenesis, we examined whether the earliest steps of the NMJ installation occur normally in myotubes from SMA patients. When cultured in low-serum medium, myoblasts are able to fuse and form multinuclear structures called myotubes, the future myofibers. In this study, we show that myoblasts from SMA I patients fuse abnormally, and that the aggregation of the nAChRs is defective in these cells. We also examine whether this lack of aggregation is due to abnormal clustering itself, or a lack of expression of the nAChR.

\section{Materials and methods}

\section{Cell Culture}

Human muscle cell cultures were established according to a previously described technique. ${ }^{31}$ Briefly, they were based on a dissociated cell suspension prepared from human muscle biopsies, plated onto cover glass slips coated with a solution of collagen diluted 100-fold in a Hanks' balanced saline solution without $\mathrm{Ca}^{2+}$ or $\mathrm{Mg}^{2+}$ (Gibco, Life technologies, Eragny, France). Cells were grown without nerves on 'aneural medium', consisting of a F14 medium (Gibco), supplemented with $2 \mathrm{mmol} / \mathrm{l}$ glutamine (Gibco), $10 \mu \mathrm{mol} / \mathrm{l}$ insulin (Sigma, L'Isles d'Abeau Chesnes, France), $10 \mathrm{ng} / \mathrm{ml}$ epidermal growth factor (Tebu, Le Perray-en-Yvelines, France), $12.5 \mathrm{ng} / \mathrm{ml}$ basic fibroblast growth factor (Tebu), $10 \%$ fetal calf serum (FCS; HyClone, Perbio Brebieres, France) and 1\% of an antibiotic-antimycotic mixture (Gibco). On day 0 of the experiment, $10^{5}$ cells were seeded on $35 \mathrm{~mm}$ Petri dish, and the following day, the aneural medium was replaced with a fusion medium containing $5 \%$ of FCS, which favors the fusion of the myoblasts into multinuclear myotubes. Cultures were maintained at $37^{\circ} \mathrm{C}$ in a $5 \%$ $\mathrm{CO}_{2}-95 \%$ air incubator.

Biopsies from embryonic origin were obtained from the Banque de Tissus pour la Recherche, Association Française contre les Myopathies, from Dr S Vasseur. 


\section{Immunoblotting}

Whole cell protein lysates were prepared after washing cells with phosphate-buffered saline and incubating at $4{ }^{\circ} \mathrm{C}$ for $10 \mathrm{~min}$ in lysis buffer (Tris $\mathrm{pH}$ 8, $20 \mathrm{mM}$, NaCl $137 \mathrm{mM}$, Igepal 1\%, Glycerol 10\%, $\mathrm{NaF} 50 \mathrm{mM}$, NaPPi $10 \mathrm{mM}$, E64, leupeptine, aprotinin, antipaïne, chymostatin). The cells were scrapped and the lysate was centrifuged at $10000 \mathrm{~g}$ for $10 \mathrm{~min}$ at $4{ }^{\circ} \mathrm{C}$. The protein concentrations were determined using the BCA protein assay kit. Protein samples (10 $\mu \mathrm{g}$ each) were separated by SDS-polyacrylamide gel electrophoresis, transferred to nitrocellulose membrane and incubated with antibodies. The secondary antibodies were coupled to HRP to allow the ECL detection (Amersham Biosciences, Saclay, France). Antibodies were used at the following dilutions: anti-actin (1:20000), anti-myo$\sin$ (1:5000), anti-MuSk (1:5000), anti-GAPDH (1:50 000).

\section{Fusion Index}

Each day within 6 days after cells seeding, three dishes of three different donors were randomly stained with the May-Grünwald-Giemsa stain and myogenic cells nuclei of 10 randomly chosen fields were counted under a contrast phase microscope. The fusion index is defined as the percentage of myogenic cell nuclei present in myotubes compared with the total number of myogenic cells nuclei present in the observed field. Observations were performed at a magnification $\times 400$.

\section{Confocal Microscopy}

At 5 days after cell seeding, a final concentration of $2 \mathrm{nmol} / \mathrm{l}$ of agrin (a gift from Dr T Maier, Myocontract, Basel, Switzerland) was added to each dish and the cultures were maintained at $37^{\circ}$ for $16 \mathrm{~h}$. A final concentration of $40 \mathrm{nmol} / \mathrm{l}$ of $\alpha$-bungarotoxin ( $\alpha$-Bgtx) Texas $\operatorname{Red}^{\circledR}$-X conjugate (Molecular Probes, Interchim, Montluçon, France) was then added and for $1 \mathrm{~h}$ at $37^{\circ} \mathrm{C}$. Cells were then fixed for $20 \mathrm{~min}$ with paraformaldehyde $3.7 \%$ in PBS at room temperature and examined by confocal microscopy. Texas $\operatorname{Red}^{\circledR}$ has an absorption wavelength of $598 \mathrm{~nm}$ and emits fluorescence at $613 \mathrm{~nm}$.

\section{nAChR Measurement by ${ }^{125}$ I-Specific Binding}

To determine the number of nAChRs, dishes were randomly divided into two equal sets. The first set received $1 \mathrm{ml}$ of culture medium containing $300 \mathrm{nmol} / \mathrm{l}$ of $\alpha$-Bgt (Sigma, France), and all dishes received ${ }^{125} \mathrm{I} \alpha$-Bgt (Amersham Biosciences, Orsay, France) diluted in culture medium to give the final concentrations from 0.25 to $8 \mathrm{nmol} / \mathrm{l}$. Cells were then incubated at $37^{\circ} \mathrm{C}$ for $30 \mathrm{~min}$. After three washes of the cell layers with $\mathrm{PBS}$ without $\mathrm{Ca}^{2+}$
$\mathrm{Mg}^{2+}, 1 \mathrm{ml}$ of $\mathrm{NaOH} 1 \mathrm{M}$ was added to each dish. In a few seconds, the cells were in suspension and they were transferred in a $5 \mathrm{ml}$ vial to determine the ${ }^{125} \mathrm{I}$ radioactivity in a $\gamma$-counter. Specific binding was determined by subtracting the radioactivity bound after saturation of binding sites with cold $\alpha$-Bgt (nonspecific binding obtained from the dishes with cold and radioactive toxin) from the total bound radioactivity (obtained from the dishes with only radioactive toxin). Scatchard analysis allowed to determine the total number of binding sites, that is, of $\mathrm{nAChR}$, in fmol per mg cell protein and the $K_{\mathrm{D}}$ in $\mathrm{nmol} / \mathrm{l}$ reflecting the affinity of the toxin for its receptor. Proteins were assayed according to the method of Bradford. ${ }^{32}$ The values of $K_{\mathrm{D}}$ and $B_{\max }$ were obtained using the Graphpad Prism 4 software.

\section{Results}

The aim of this study was to compare muscle cells of control individuals and SMA I, II or III patients in order to demonstrate abnormalities inherent to the muscular compartment, without any nerve element. All experiments were carried out in parallel for every type of donor and each condition was repeated in triplicate in independent cultures with different donors for statistical significance. Statistical analyses were performed by one way ANOVA with subsequent Fischer test.

\section{Proliferation and Differentiation}

Cells were seeded in conditions allowing fusion to occur. No difference could be highlighted between control and SMA I muscle cells in terms of proliferation (Figure 1a). The number of cells increased in parallel between the two kinds of cells. In such conditions, the maximum fusion index was reached at day 5 (D5) with $55.7 \pm 7.6 \%$ of nuclei present in myotubes for control cells (Figure 1b). No difference could be demonstrated between the fusion index of control, SMA III and SMA II cells (data not shown). In contrast, for cells from SMA I patients, the fusion index reached a maximum of $25.4 \pm 9.2 \%$ at D6. Fusion indices were significantly different between control and SMA I cells at D4, D5 and D6. This lack of fusion was obvious by inspection of the cultures (Figure 2a). On D5, the cultures of control cells showed myotubes with numerous nuclei (arrowheads), whereas cultures from SMA I cells presented very few multinuclear structures. This lack of fusion cannot be attributed to a problem in the actin-myosin expression as both types of myotubes express the same level of actin and myosin (Figure 2b). In conclusion, skeletal muscle cells from SMA I patients did not fuse normally.

Based on this result, the following experiments were performed when the fusion index was the highest, on D5. 


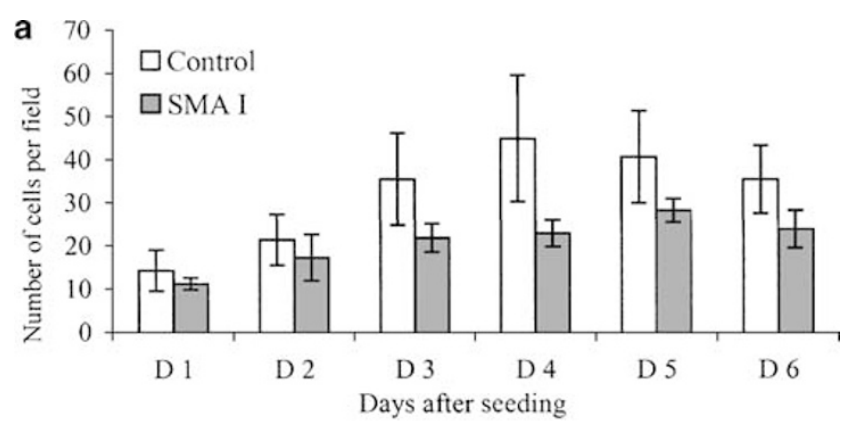

$2.28 \pm 1.89$ for the SMA III cells, $2.27 \pm 1.47$ for the SMA II cells and $2.41 \pm 1.49$ for the SMA I cells. In terms of $B_{\max }$ (Figure 5a), no difference was observed between SMA III and SMA II myotubes compared to the control ones. The number of nAChR expressed by the myotubes of SMA I patients $\left(B_{\max }=61.36 \pm 27.56 \mathrm{fmol} / \mathrm{mg}\right.$ prot$)$ was significantly lower than those expressed by the control myotubes $\left(B_{\max }=920.44 \pm 352.7 \mathrm{fmol} / \mathrm{mg}\right.$ protein $)$. However, the level of expression of other proteins such as MuSK is not altered in SMA I myotubes with or without agrin treatment (Figure 5b). GAPDH expression is the same in control or SMA I myotubes, suggesting a problem inherent to AChR expression itself.

In conclusion, the affinity of $\alpha$-Bgtx for its receptor was shown to be equivalent for all types of muscle cells, but SMA I muscle cells expressed far fewer (at least 10-fold less) nAChRs than controls, which could explain reduced nAChR clustering observed by confocal microscopy.

\section{Discussion}

Figure 1 Proliferation (a) and Fusion index (b) of muscle cells from control and SMA I donors. Cells were stained with the MayGrünwald-Giemsa staining and observed under a phase microscope. Proliferation was determined by counting the total cell number present in the observed field. The fusion index was defined as the number of nuclei present in myotubes in comparison with the total number of nuclei present in the observed field. Data are represented as mean \pm standard deviation ( $n=3$ different donors for each kind of cells, 10 fields randomly chosen per dish). ${ }^{*} P<0.05$ in comparison with the control cells at the same day (Fisher's test in one-way ANOVA).

\section{nAChRs Aggregation}

Myotube cultures were treated with soluble agrin and then with $\alpha$-Bgtx Texas $\operatorname{Red}^{\mathbb{R}}$-X conjugate. Observation of the cells by confocal microscopy showed that the agrin induces nAChR aggregates in control cells (Figure 3a), but these clusters were not present or farless in the SMA I myotubes (Figure 3b). We showed here that the fusion defect demonstrated in the previous experiments affected one of the earliest steps of the NMJ installation, the agrininduced nAChR clustering.

\section{nAChR Number}

The next question was to know whether the lack of aggregation was due to a defect in the aggregation process itself, or whether the myotubes from SMA I patients expressed fewer nAChR in comparison with the control ones. Accordingly, we performed a specific binding experiment on different types of myotube cultures. Scatchard analysis (Figure 4) allowed us to determine the apparent $K_{\mathrm{D}}$ (reflecting the affinity) and the maximum binding $\left(B_{\max }\right)$ of $\alpha$ Bgtx for nAChR. The affinity of $\alpha$-Bgtx for its receptor was equivalent in each type of muscle cell. The $K_{\mathrm{D}}$ values were $2.02 \pm 0.66$ for the control cells,

The NMJ is a highly specialized synapse, allowing contact between neurons and their target cells, the muscles. SMN protein may play an essential role in neuromuscular maturation, not only in neurite outgrowth but in the muscle component too. The SMN deficiency in neurons and muscles may each contribute to the pathogenesis of SMA. ${ }^{33}$

In this study, we demonstrated that in the absence of any nerve component, muscle cells from SMA I patients presented abnormalities that may affect NMJ installation.

Nerve terminals contain vesicles that release acetylcholine molecules, which diffuse across the synaptic cleft and activate nAChRs in the muscle postsynaptic membrane. These receptors must be present at high density in the muscle component precisely in the opposite site of acetylcholine release from the nerve to ensure rapid and precise synaptic transmission. Thus, one of the earliest events in synapse formation is the clustering of the nAChRs that is under a tight temporal and spatial regulation. ${ }^{34,35}$ Previously, the nerve and its derivatives were thought to be the key actors of the postsynaptic differentiation, particularly the nAChRs clusters, but recently the muscle was also shown to play an essential role. ${ }^{36}$ It was shown that nAChRs clustering could occur without motoneurons and that the muscles presented a prepatterning program able to induce nAChRs aggregation without any nerve component. ${ }^{37}$ Agrin, a multidomain proteoglycan released by nerves, is responsible for clustering of pre-existing nAChRs. ${ }^{24}$ Neural agrin is necessary to obtain functional synapses. This protein has numerous functions, including the redistribution of pre-existing nAChRs and the synthesis of nAChRs through its interaction with the neur- 
a

\section{Day 1}

C
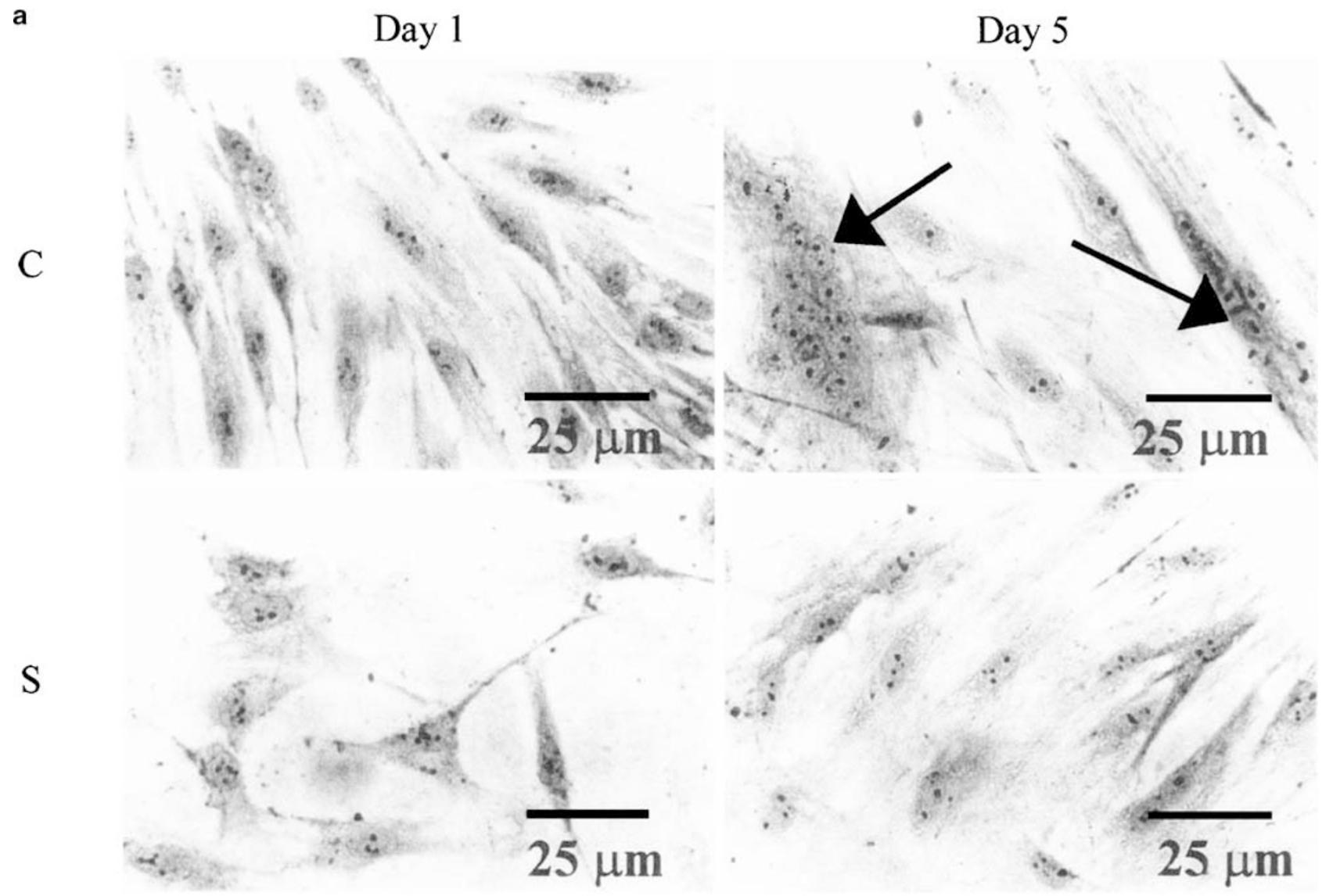

b

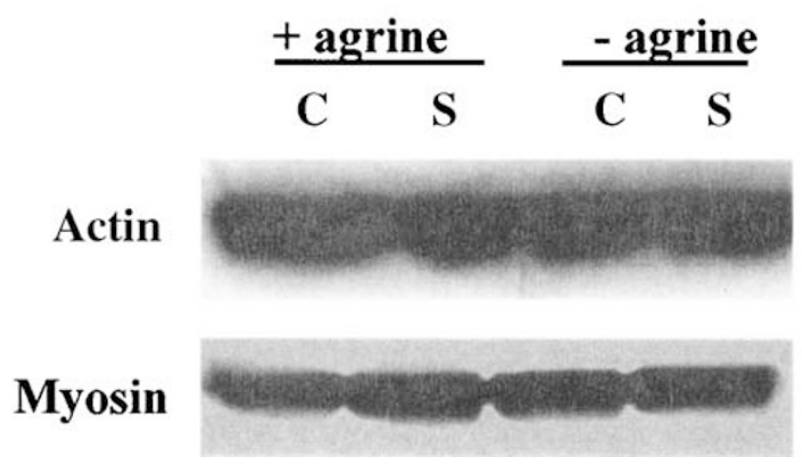

Figure 2 Fusion of muscle cells coming from control (C) or SMA I (S) Donors. (a) Phase-contrast microphotographs of muscle cells 1 day (D1) and 5 days (D5) after cell seeding. Cells from control (C) and SMA I (S) patients were MGG stained. After 5 days of culture in a medium poor in FCS, human muscle cells are able to fuse to form myotubes with numerous nuclei (arrowhead). (b) Immunoblots for myosin and actin using whole cell protein lysates. Analogous results were observed for (a) and (b) in three independent experiments.

egulin-1. ${ }^{38}$ Agrin interacts with numerous proteins including rapsyn, which represents a downstream regulator of $n A C h R s$ clustering ${ }^{39}$ and the MuSK, a component of the agrin receptor. ${ }^{40-42}$ It was shown that all of these proteins form a preassembled complex and that myotubes have the intrinsic ability to assemble the nAChR protein complex in the absence of motoneuron. ${ }^{37}$ In response to agrin, MuSk undergoes autophosphorylation and the $\beta$ subunit of the AChR is phosphorylated.
We performed this study on muscle cells from embryonic origin alone, without any nerve component, and showed intrinsic defects in these cells. We confirmed our previous data suggesting that the skeletal muscles were targets of the SMN defects in the SMA disease. In the first experiment, we showed that the myoblasts from SMA I patients had normal proliferation, but they did not fuse normally. They formed myotubes with a very few number of nuclei (Figures 1 and 2). The SMN protein seems to be 

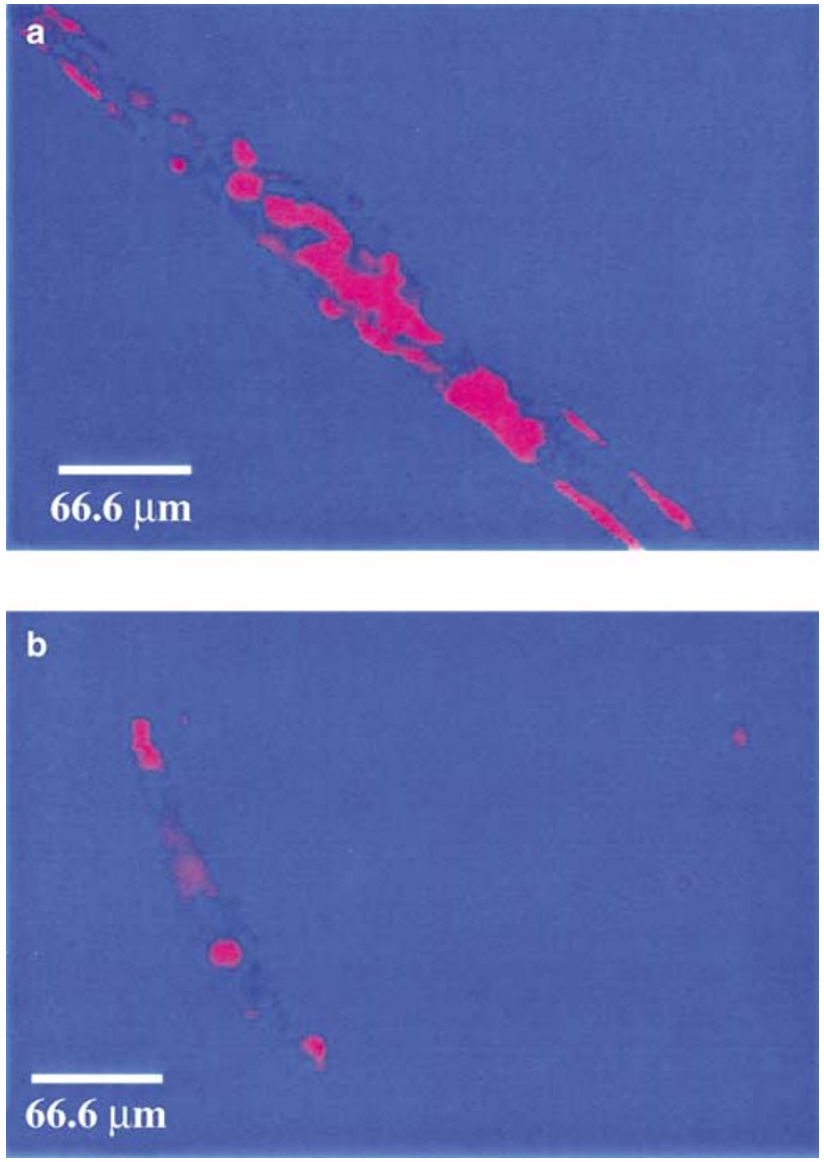

Figure 3 Agrin-induced nAChR aggregation on human muscle cells. Confocal observation of myotubes from control (a) or SMA I (b) myotubes treated with agrin and $\alpha$-Bgtx Texas $\operatorname{Red}^{\mathbb{R}}$ conjugate to see the nAChRs aggregates.

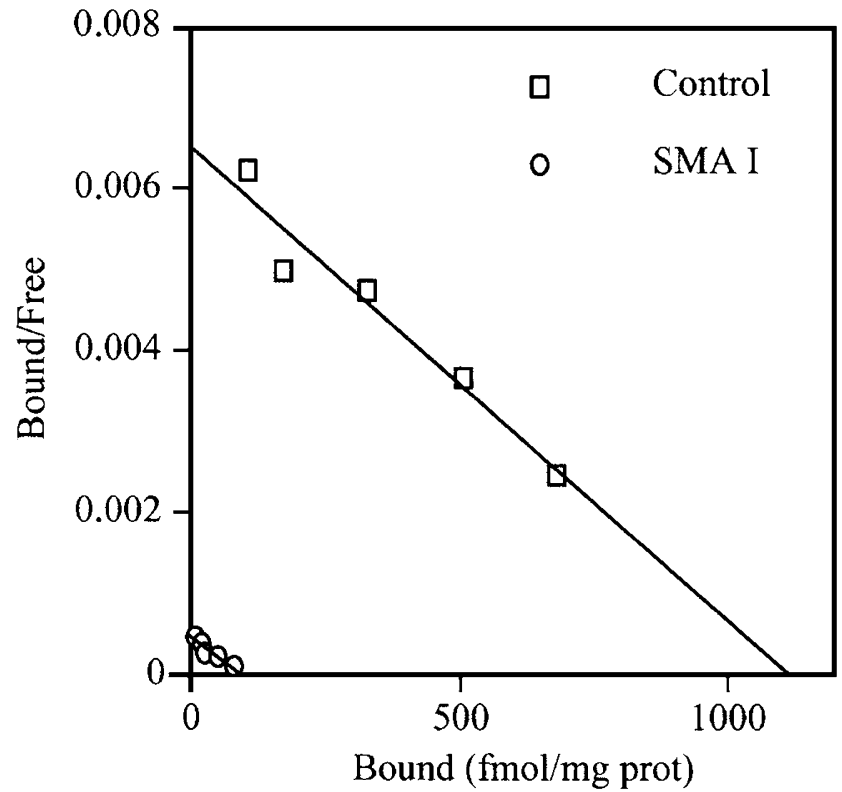

Figure 4 Scatchard analysis of the binding assay for control and SMA I donors. Binding values were obtained using the Graphpad Prism4 software. The graph represents results obtained for one experiment, but the pharmacological constants were calculated starting from three independent experiments.

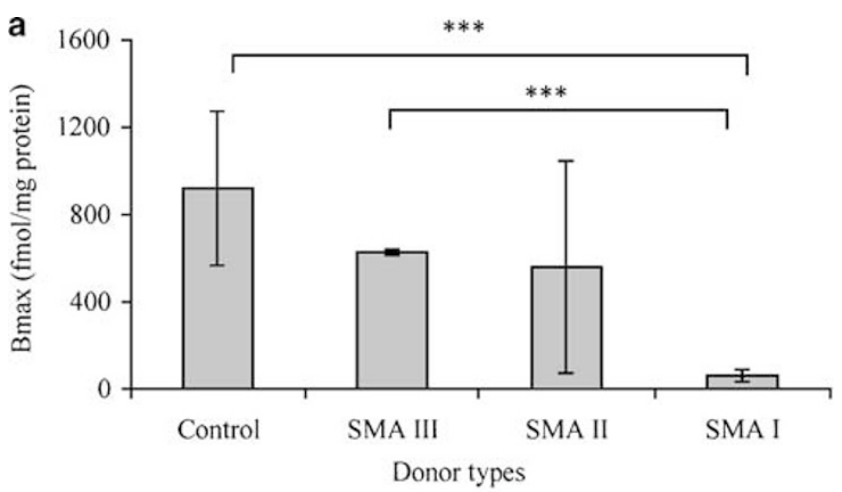

b

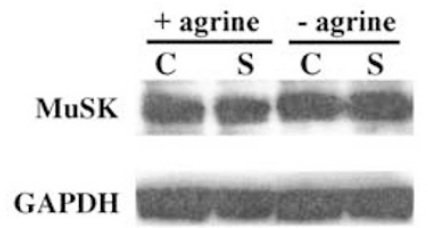

Figure 5 (a) $B_{\max }$ values of $\alpha$-Bgtx for the nAChRs of myotubes from control individuals or SMA I, II or III patients. Values were deduced from the Scatchard plots carried out for each experiment. All data were expressed as mean \pm standard deviation $(n=3) .{ }^{*} P<0.05$ (Fischer's test in one-way ANOVA). (b) Immunoblots for MuSK and GAPDH using whole cell protein lysates of control (C) and SMA I (S) donors. Analogous results were observed in three independent experiments.

necessary for the muscle cell differentiation, but the lack of SMN in SMA patients seems to have no consequence on cell proliferation. This finding confirms that the of myotubes of the SMA I patients are immature $^{43}$ and is consistent with a study showing that expression of myf-5, a member of the muscle-regulatory factor family, is abnormal in embryonic SMA myogenic cells. ${ }^{20}$ Thus, myogenesis is not appropriately regulated in SMA, but the proteins involved in contraction, such as actin and myosin are normally expressed (Figure 2b). A synchronized rate of muscle maturation with that of the motor activity is critical for the development of the NMJ. If maturation is slower in either motoneurons or muscles, the neuromuscular system will probably develop permanent damage. ${ }^{44}$

The fact that muscle cells from SMA I patients are defective in nAChRs aggregation (Figure 3) proved that the NMJs could not be correctly installed and as this event occured very early in the development, confirmed that SMA is an embryo-fetal disease. We proved that this lack of aggregation was due to a lack of expression of the nAChR protein (Figure 5), whereas the binding affinity remained unchanged. Moreover, the other protein important in the NMJ installation, MuSK, is not affected in SMA phenotype (Figure 5b). Thus, only AChR expression is impaired in muscle cells from SMA I patients. Neuregulin-1 is a protein able to induce transcription of $n A C h R$ subunits in myotubes. ${ }^{45}$ It might be interesting to associate neuregulin-1 with the soluble agrin in the experiment of agrin-induced nAchRs clustering and look for an eventual effect on nAChRs 
expression in the SMA I myotubes. It will also be necessary to study other proteins involved in the NMJ installation such as rapsyn. The lack of expression of $\mathrm{nAChR}$ could be related to a reduced number of motor units in SMA patients. ${ }^{46}$ The muscle cells from SMA patients express lower levels of nAChRs, leading to a fewer number of motor units, but those that are present are more extended to counterbalance this phenomenon.

In conclusion, this study highlights reduced expression of the nAChR protein, which represents a very important defect inherent to the muscle cells of SMA I patients. This shows that in the earliest step of the NMJ installation, the muscle component in SMA I patients is defective, thus supporting its role in the pathogenesis of the disease. Future therapeutic efforts leading to restoration of the SMN protein level should consider this tissue as a candidate for SMA treatments.

\section{Acknowledgements}

This work was supported by a grant from the Association Française contre les Myopathies (AFM Grant 2002), and a studentship from the Région Alsace for AS Arnold.

\section{References}

1 Munsat T. Workshop report: international SMA collaboration. Neuromusc Disord 1991;1:81.

2 Brzustowicz LM, Lehner T, Castilla LH, et al. Genetic mapping of chronic childhood-onset spinal muscular atrophy to chromosome 5q11.2-13.3. Nature 1990;344: 540-541.

3 Gilliam TC, Brzustowicz LM, Castilla LH, et al. Genetic homogeneity between acute and chronic forms of spinal muscular atrophy. Nature 1990;345:823-825.

4 Melki J, Abdelhak S, Sheth P, et al. Gene for chronic proximal spinal muscular atrophies maps to chromosome 5q. Nature 1990;344:767-768.

5 Melki J, Lefebvre S, Burglen L, et al. De novo and inherited deletions of the $5 q 13$ region in spinal muscular atrophies. Science 1994;264:1474-1477.

6 Lefebvre S, Burglen L, Reboullet S, et al. Identification and characterization of a spinal muscular atrophydetermining gene. Cell 1995;80:155-165.

7 Liu Q, Dreyfuss G. A novel nuclear structure containing the survival of motor neurons protein. EMBO J 1996;15:3555-3565.

8 Liu Q, Fischer U, Wang F, et al. The spinal muscular atrophy disease gene product, SMN, and its associated protein SIP1 are in a complex with spliceosomal snRNP proteins. Cell 1997;90:1013-1021.

9 Paushkin S, Gubitz AK, Massenet S, et al. The SMN complex, an assemblyosome of ribonucleoproteins. Curr Opin Cell Biol 2002;14:305-312.

10 Charroux B, Pellizzoni L, Perkinson RA, et al. Gemin3: a novel DEAD box protein that interacts with SMN, the spinal muscular atrophy gene product, and is a component of gems. J Cell Biol 1999;147:1181-1194.
11 Fischer U, Liu Q, Dreyfuss G. The SMN-SIP1 complex has an essential role in spliceosomal snRNP biogenesis. Cell 1997;90:1023-1029.

12 Pellizzoni L, Kataoka N, Charroux B, et al. A novel function for SMN, the spinal muscular atrophy disease gene product, in pre-mRNA splicing. Cell 1998;95: 615-624.

13 Coovert DD, Le TT, McAndrew PE, et al. The survival motor neuron protein in spinal muscular atrophy. Hum Mol Genet 1997;6:1205-1214.

14 Lefebvre S, Burglen P, Liu Q, et al. Correlation between severity and SMN protein level in spinal muscular atrophy. Nat Genet 1997;16:265-269.

15 Burlet P, Huber C, Bertrandy S, et al. The distribution of SMN protein complex in human fetal tissues and its alteration in spinal muscular atrophy. Hum Mol Genet 1998;7:1927-1933.

16 Askanas V, Kwan H, Alvarez RB, et al. De novo neuromuscular junction formation on human muscle fibres cultured in monolayer and innervated by foetal rat spinal cord: ultrastructural and ultrastructuralcytochemical studies. J Neurocytol 1987;16:523-537.

17 Braun S, Croizat B, Lagrange MC, et al. Constitutive muscular abnormalities in culture in spinal muscular atrophy. Lancet 1995;345:694-695.

18 Braun S, Croizat B, Lagrange MC, et al. Degeneration of cocultures of spinal muscular atrophy muscle cells and rat spinal cord explants is not due to secreted factors and cannot be prevented by neurotrophins. Muscle Nerve 1997;20:953-960.

19 Guettier-Sigrist S, Coupin G, Braun S, et al. Muscle could be the therapeutic target in SMA treatment. J Neurosci Res 1998;53:663-669.

20 Guettier-Sigrist S, Coupin G, Braun S, et al. On the possible role of muscle in the pathogenesis of spinal muscular atrophy. Fundam Clin Pharmacol 2001; 15:31-40.

21 Cifuentes-Diaz C, Frugier T, Tiziano FD, et al. Deletion of murine SMN exon 7 directed to skeletal muscle leads to severe muscular dystrophy. J Cell Biol 2001;152:1107-1114.

22 Nicole S, Desforges B, Millet G, et al. Intact satellite cells lead to remarkable protection against Smn gene defect in differentiated skeletal muscle. J Cell Biol 2003;161:571-582.

23 Lin W, Burgess RW, Dominguez B, et al. Distinct roles of nerve and muscle in postsynaptic differentiation of the neuromuscular synapse. Nature 2001;410: 1057-1064.

24 McMahan UJ. The agrin hypothesis. Cold Spring Harb Symp Quant Biol 1990;55:407-418.

25 Reist NE, Werle MJ, McMahan UJ. Agrin released by motor neurons induces the aggregation of acetylcholine receptors at neuromuscular junctions. Neuron 1992;8:865-868.

26 Ruegg MA, Bixby JL. Agrin orchestrates synaptic differentiation at the vertebrate neuromuscular junction. Trends Neurosci 1998;21:22-27.

27 Glass DJ, Bowen DC, Stitt TN, et al. Agrin acts via a MuSK receptor complex. Cell 1996;85:513-523.

28 Wallace BG, Qu Z, Huganir RL. Agrin induces phosphorylation of the nicotinic acetylcholine receptor. Neuron 1991;6:869-878.

29 Wang Y, Miller AL, Mooseker MS, et al. The Ablrelated gene (Arg) nonreceptor tyrosine kinase uses two F-actin-binding domains to bundle F-actin. Proc Natl Acad Sci USA 2001;98:14865-14870. 
30 Jones MA, Werle MJ. Agrin-induced AChR aggregate formation requires CGMP and aggregate maturation requires activation of cGMP-dependent protein kinase. Mol Cell Neurosci 2004;98:195-204.

31 Arnold AS, Gueye M, Ronde P, et al. Construction of a plasmid containing human SMN, the SMA determining gene, coupled to EGFP. Plasmid 2002;47:79-87.

32 Bradford MM. A rapid and sensitive method for the quantitation of microgram quantities of protein utilizing the principle of protein-dye binding. Anal Biochem 1976;72:248-254.

33 Fan L, Simard LR. Survival motor neuron (SMN) protein: role in neurite outgrowth and neuromuscular maturation during neuronal differentiation and development. Hum Mol Genet 2002;11:1605-1614.

$34 \mathrm{Huh} \mathrm{KH}$, Fuhrer C. Clustering of nicotinic acetylcholine receptors: from the neuromuscular junction to interneuronal synapses. Mol Neurobiol 2002;25:79-112.

35 Sanes JR, Lichtman JW. Development of the vertebrate neuromuscular junction. Annu Rev Neurosci 1999;22: 389-442.

36 Willmann R, Fuhrer C. Neuromuscular synaptogenesis: clustering of acetylcholine receptors revisited. Cell Mol Life Sci 2002;59:1296-1316.

37 Yang X, Arber S, William C, et al. Patterning of muscle acetylcholine receptor gene expression in the absence of motor innervation. Neuron 2001;30:399-410.

38 Trinidad JC, Fischbach GD, Cohen JB. The agrin/MuSK signaling pathway is spatially segregated from the neuregulin/ErbB receptor signaling pathway at the neuromuscular junction. J Neurosci 2000;20:8762-8770.
39 Apel ED, Glass DJ, Moscoso LM, et al. Rapsyn is required for MuSK signaling and recruits synaptic components to a MuSK-containing scaffold. Neuron 1997;18:623-635.

40 DeChiara TM, Bowen DC, Valenzuela DM, et al. The receptor tyrosine kinase MuSK is required for neuromuscular junction formation in vivo. Cell 1996;85:501512.

41 Jennings CG, Dyer SM, Burden SJ. Muscle-specific trkrelated receptor with a kringle domain defines a distinct class of receptor tyrosine kinases. Proc Natl Acad Sci USA 1993;90:2895-2899.

42 Valenzuela DM, Stitt TN, DiStefano PS, et al. Receptor tyrosine kinase specific for the skeletal muscle lineage: expression in embryonic muscle, at the neuromuscular junction, and after injury. Neuron 1995;15: 573-584.

43 Hausmanowa-Petrusewicz I, Karwanska A. Electromyographic findings in different forms of infantile and juvenile proximal spinal muscular atrophy. Muscle Nerve 1986;9:37-46.

44 Vrbova G, Navarrete R, Lowrie M. Matching of muscle properties and motoneurone firing patterns during early stages of development. J Exp Biol 1985;115:113123.

45 Fischbach GD, Rosen KM. ARIA: a neuromuscular junction neuregulin. Annu Rev Neurosci 1997;20: 429-458.

46 Galea V, Fehlings D, Kirsch S, et al. Depletion and sizes of motor units in spinal muscular atrophy. Muscle Nerve 2001;24:1168-1172. 